\title{
A NEW SPECIES OF DESMOPACHRIA (S. STR.) FROM THE ANTILLEAN-CARIBBEAN REGION (COLEOPTERA: DYTISCIDAE)*
}

\author{
By Frank N. YounG**
}

The small beetle described below is probably classified in many collections as either Desmopachria grana (Aubé) or Desmopachria nitida Babington. However, the male external genitalia (Fig. 1) are unique among the species of the typical subgenus of Desmopachria. The species is closest to Desmopachria glabricula Sharp, but the genitalia are distinctive (Fig. 2).

I take pleasure in dedicating this species to my friend and mentor, the late Phillip J. Darlington, Jr.

\section{Desmopachria (s. str.) darlingtoni sp. nov.}

Diagnosis: a small species resembling Desmopachria (s. str.) grana LeConte, but more oval, more attenuate behind in dorsal aspect, and with a vague sutural stria of coarse punctures. The male genitalia (Fig. 1) are unique.

Holotype Male: ovate, attenuate behind in dorsal aspect. Total length $1.36 \mathrm{~mm}$; greatest width near middle third of elytra about $0.88 \mathrm{~mm}$; width of pronotum at base $0.64 \mathrm{~mm}$; width of pronotal apex about $0.40 \mathrm{~mm}$; length of pronotum at midline about $0.24 \mathrm{~mm}$. Head finely and rather sparsely punctate with a few irregular larger punctures; clypeal impressions with coarser punctures extending backward almost straight from the margin and not reaching or curving toward the margins of the eyes. No visible microsculpture on head, body, or other parts at $90 \times$ magnification. Pronotum with punctation on disk similar to that of disk of head, but with slightly irregular, coarser, and closer punctations along anterior and posterior margins. Elytra with setigerous punctures about as coarse or coarser than those of anterior and posterior pronotal margins; tiny setae visible on disk at $90 \times$ magnification; elytral punctures on disk

\footnotetext{
*Contribution from the biological laboratories of Indiana University, aided by grants from NSF, NHI, and Indiana University Foundation.

**Professor Emeritus of Biology, Indiana University, Bloomington, Indiana 47405. Manuscript received by the editor July 2, 1989.
} 
in irregular rows, the rows nearest suture somewhat impressed suggesting vague sutural striae; elytral punctation finer and sparser laterally and posteriorly as unusual. Coxal lamina and abdominal sternites very finely almost imperceptibly punctate, shining; last visible sternite with some coarser punctures. Color of head and pronotum largely clear yellowish brown or brownish yellow, the pronotum narrowly darker along base. Elytra dark reddish brown darker along suture; venter light yellowish brown, darker along sutures as usual.

Allotype female similar to male in punctation and body shape, but somewhat lighter colored on elytra which, however, contrast with the lighter pronotum and head. Prosternal process similar to male. Size similar, total length $1.44 \mathrm{~mm}$; greatest width near basal one-third of elytra about $0.88 \mathrm{~mm}$; pronotal base about 0.68 ; pronotal apex about $0.40 \mathrm{~mm}$; pronotum at midline about $0.28 \mathrm{~mm}$.

Variation: The male genitalia appear to be identical over a wide area in the Antilles and northern Colombia. Some specimens in the paratype series have vague suggestions of lighter markings on the elytra, but in the holotype the markings appear to be due to transmitted light through the integument reflecting internal structures. Nearly all specimens seen except the holotype are slightly teneral. The vague sutural stria is also variable.
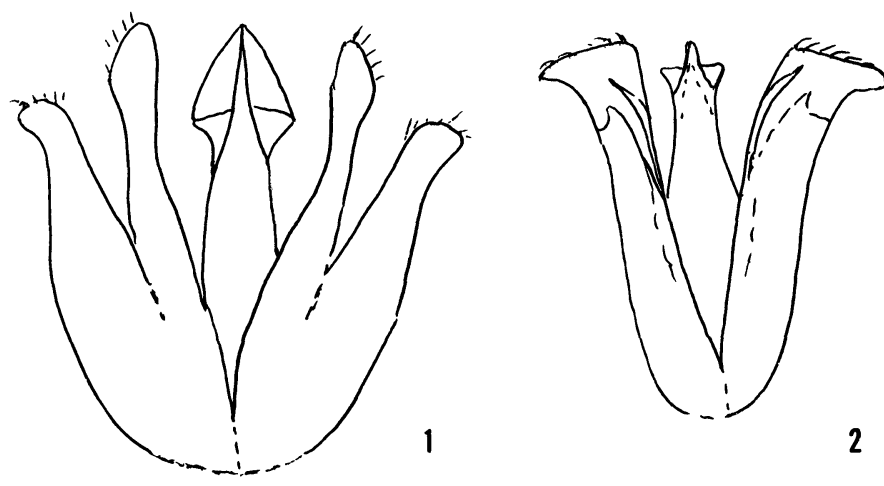

Fig. 1. Desmopachria darlingtoni sp. nov., ventral aspect in copulatory position of male external genitalia. Holotype male.

Fig. 2. Desmopachria glabricula Sharp, same. 
Holotype and allotype from: Jamaica, Ochs Rio, August 20-24, 1934, P. J. Darlington, Jr. in Museum of Comparative Zoology, Harvard University, Cambridge, Massachusetts (MCZ).

Paratypes (45) from: Cuba, Oriente Province, Baracoa, 12 July, 1936, PJD Jr. MCZ (2) Dominican Republic Sanchez, July 1938 (19) PJD Jr. MCZ. Haiti, Miragone, 2 Nov. 1934 PJD Jr. (2) MCZ; Etang Lachauz, S. W. Peninsula under 1000 ft., 26 Oct. 1937, PJD Jr. (2) MCZ. Colombia, Magdalena, Aracateca, PJD Jr. (8) MCZ; Magdalena, Rio Frio, PJD Jr. (12) MCZ. 

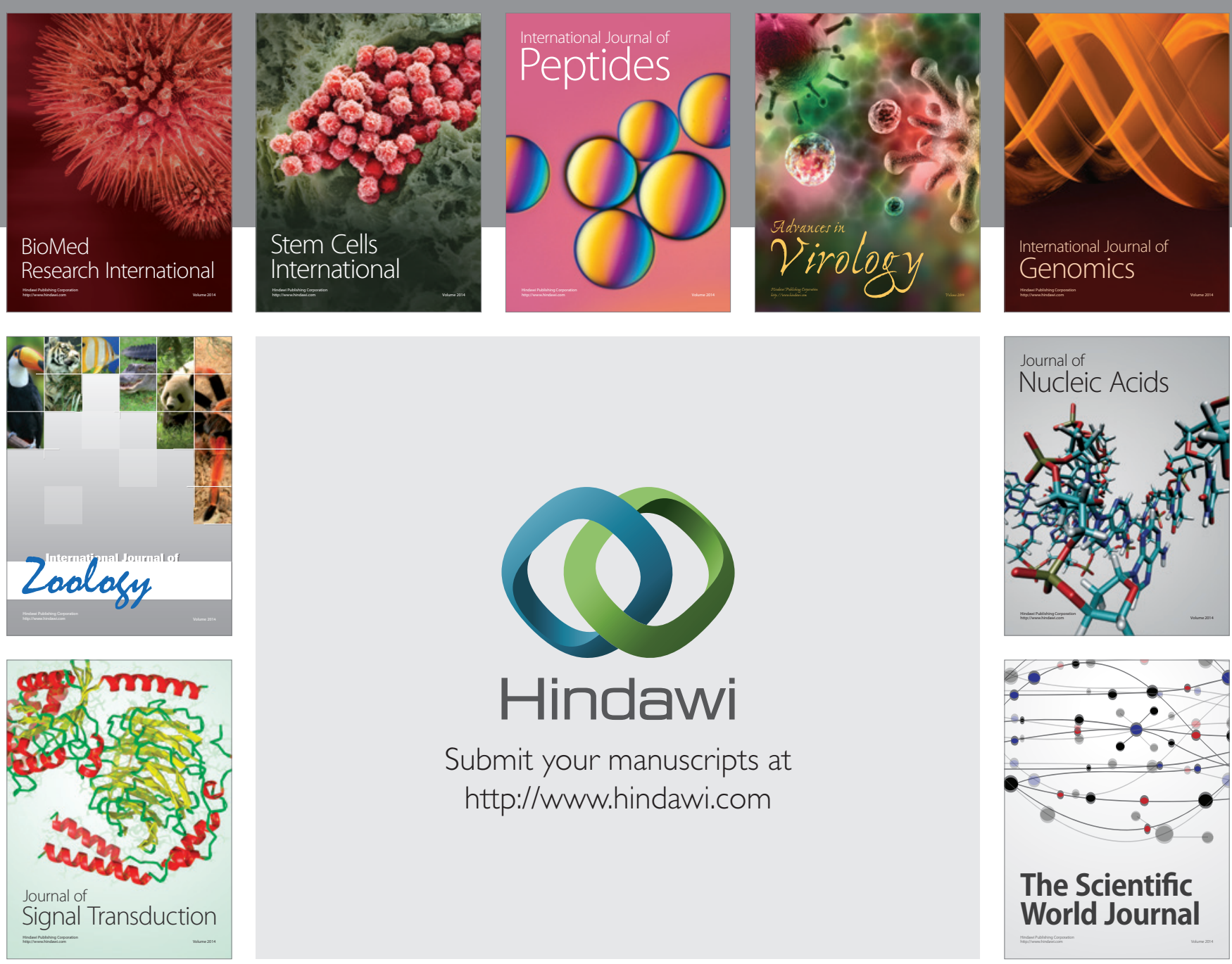

Submit your manuscripts at

http://www.hindawi.com
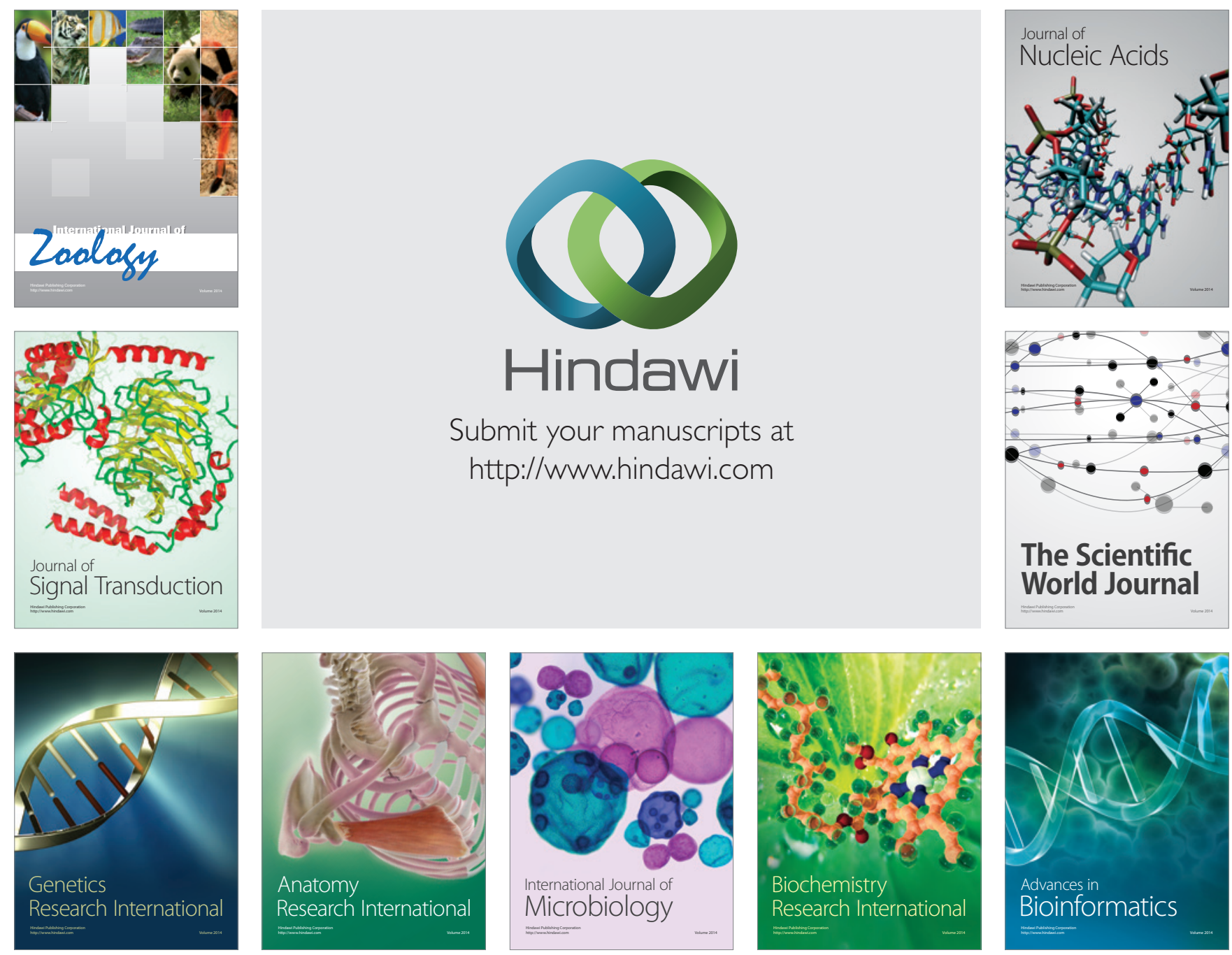

The Scientific World Journal
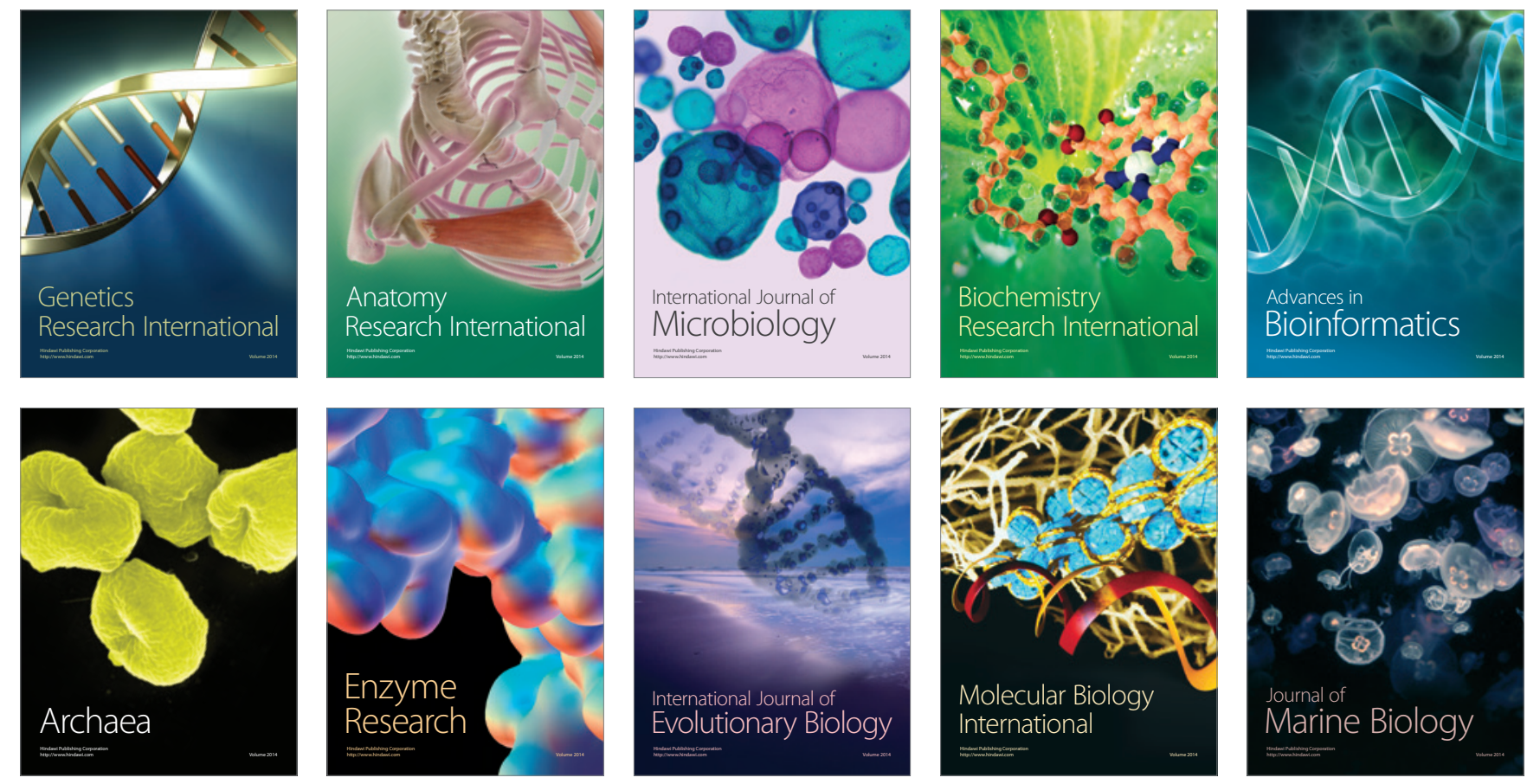